\title{
Wound Care Management and Dressing Materials
}

\author{
Sriyani A Kumarasinghe* \\ Department of Nursing Faculty of Health Sciences, The Open University of Sri Lanka, Sri Lanka
}

*Corresponding author: Sriyani A Kumarasinghe RN, BScN (Hons), Dip Teaching \& Supervision, PhD Senior Lecturer, Department of Nursing Faculty of Health Sciences, The Open University of Sri Lanka, Nawala, Nugegoda, Sri Lanka

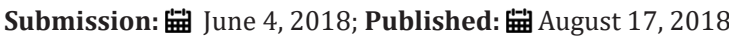

\begin{abstract}
Impairment of wound healing has many negative outcomes for the patient, family and to the society. Therefore, wounds need to be managed comprehensively through proper assessment, following proper techniques and, using proper dressings according to the nature of the wound and patient preferences. Careful assessment of the wound is vital to determine the healing progress and, to select the type of material to be used for the dressing. Pain assessment and its control are un-forgetful aspects of successful wound management. Though advanced dressing materials are available in facilitated settings, conventional wound materials including topical antibacterial agents are widely used in most of the settings due to unavailability, low cost, and unawareness. In this review, briefly discuss the general principles of wound management, principles of wound bed preparation, dressing selection, antibacterial agents and dressing materials using for wound care.
\end{abstract}

Keywords: Wound care management; Dressing selection; Dressing materials; Advanced dressings

\section{General Principles of Wound Management}

A comprehensive assessment of an individual with a wound should cover both intrinsic and extrinsic factors [1] which are potential to impact on wound healing. It should follow by regular on-going assessment to ascertain any changes require treatment in relation to patient factors and/or wound factors. Usually, wounds are potentially painful. In order to promote wound healing it is necessary to control pain after careful assessment. Proper assessment helps in identifying factors which are deteriorating the wound, and in diagnosing etiology or complications. Followed by proper pain assessment, suitable measures may require managing the pain by considering local, regional or systemic patient factors to control it. It is also recommended that aseptic wound cleansing technique is used for individuals with immune compromised and for wounds which enter the body cavity. Also, patients' referral is mandatory to obtain a more detailed diagnostic assessment when necessary, usually after results of initial assessment or evaluation of response to the current treatment regimen to a multidisciplinary team. Documentation is another important aspect. It should be clear and comprehensive, and that meet legal requirement and local policies and guidelines [2].

\section{Wound Care}

Wound care is the most focused aspects of the wound management and it plays a fundamental role in diabetic foot ulcer care. Wound dressings are an integral aspect of wound management and mainstay of treatment [3]. Principles of wound bed preparation involve moisture balance, minimization of inflammation, infection control, and epithelial edge advancement are directed to improve wound healing through epidermal migration, angiogenesis, and connective tissue synthesis [4]. Usually, dressings provide a moist environment to wound, protect from secondary infections, remove exudates, promote tissue regeneration [5], facilitates gaseous exchange [6], control wound odor, provide thermal insulation and mechanical protection. Thus, use of single dressing is not applicable for the entire period of wound healing [7].

\section{Dressing Selection}

Dressings which are most appropriate in successfully managing exudates and balance in wound bed environment are most vital aspects of promoting healing. Since a single type of dressing is not appropriate for throughout the journey of wound healing, selection of an appropriate dressing for the diabetic ulcer should be carefully decided. Moreover, pain and trauma at dressing changes, compatibility of other therapies and QoL and wellbeing of the patients are to be considered [8]. In addition, it is essential to be considered the cost-effectiveness and availability of dressings, and patients' preferences [3].

\section{Dressing Materials}

Standard dressing care for treating diabetic ulcers is known to be the use of wet-to-dry or wet-to-moist saline gauze dressings. This dressing is very absorptive and adherent, as well as has good ability 
in debriding the wound bed. It is a one of the less expensive widely used dressing in the world [9]. This dressing is very popular in Sri Lanka and still use as standard care even in the developed country like US [10]. However, it does not provide an effective barrier for contaminants and bacteria. When using gauze dressing, based on the wound severity it is suggested to change the dressing frequently (two to three times a day) $[9,10]$. Also moistened the dressings before removal using a gentle cleanser (usually normal saline) prevent possible bleeding [9] and to minimize wound irritation and discomfort [11]. Iodine is a highly effective, easy to use a topical antimicrobial agent which can use for both acute and chronic wounds $[12,13]$. Two preparations of iodophors mostly used in dressing are Povidone Iodine (formulations of a solution, cream, ointment, spray) and Cadexomer Iodine (Iodosorb and Idoflex). Povidone-iodine (PVP-I) is a combination of molecular iodine and polyvinylpyrrolidone surfactant/iodine complex [13] while Cadexomer Iodine is an iodine and polysaccharide complex [12]. Povidone-iodine (10\%) is an inexpensive antiseptic solution and mostly used in dressing in the Sri Lankan clinical practice. The effectiveness of Povidone-iodine in the clinical practice is still in the debate due to perceived issues with toxicity, absorption and delayed healing [12]. However, review studies found that iodine still has a room in the wound management especially when a presence of an infection [13], highly effective for antimicrobials and improve wound healing rates [12]. Another review study has concluded that iodine as an effective antiseptic and does not cause for delaying healing especially in chronic and burns wounds [14].

\section{Antibacterial Agents}

Topical Antibacterial agents widely used for diabetic ulcers in Sri Lanka are Povidone iodine and metronidazole gel. Topical antibacterial agents are less toxic and have good antibacterial coverage with either can use alone or in a combination. One of the widely used such an agent is Metronidazole gel (0.75--.80\%) which provides high gram-negative anaerobic coverage [15] good moisture for the wound bed and help to control wound odor [16]. It can use on daily basis or more often appropriately. Experimental studies on rats have shown that metronidazole is effective in wound healing by stimulating collagen production and angiogenesis [17] and early epithelialization [18].

\section{Advanced Dressings}

Although patients are required, only less than $50 \%$ of patients receive modern moist wound dressings appropriate [19] due to high cost, unavailability and knowledge deficit especially in health care providers who involved in the routine care of the patients [20]. Consequently, extensively patients receive inappropriate dressings, mainly gauze-based ones, which provide minor support for healing [20]. During the past few decades, numbers of novel dressing have been produced and tested to combat the problem of impaired healing of diabetic ulcers [5]. These dressings introduced to facilitate not only to balance moisture of the wound bed but also to help for protease action, stimulate growth factors, improve permeability of oxygen and autolytic debridement which supports for granulation and re-epithelialization process [7], prolonged time of action and high efficiency [5]. The main categories of topical regimens use in the current practice for treating for diabetic ulcers includes films, hydrogels, hydrocolloids, alginates, foams, and silver-impregnated dressings [7], growth factors, and silicon impregnated non-traumatic dressings and etc [9].

Choice of dressing for highly exudate ulcers is moisture- absorbing materials such as alginates, foams $[7,9,10]$ collagen-alginate combinations, carboxymethyl cellulose material [10] or gauze $[9,10]$. Hydrogels are effective to absorb low to moderate exudates and rehydrate the wound [9]. However, hydrogels are not recommended for highly exudate wound due to the potential for maceration [21]. Hydrocolloids show benefit for different wound bed conditions including necrotic, sloughy, granulating and epithelializing wounds. Occlusive hydrocolloid dressings are not suggested for highly exuding ulcers located in weight-bearing areas of the foot [10]. Both hydrogels and hydrocolloids dressings should be cautiously used for infected wounds [7]. Although numbers of types of dressings available in the current practice in treating diabetic ulcers show some efficacy, existing reviews have not found a single type of dressing superior to others in healing DFUs [22-24] treated in any setting. In a systematic review of Cochrane, five RCTs $(n=535)$ were studied to compare effects of hydrocolloids with four types of dressings including antimicrobial (silver) fibrous, standard alginate dressing, an antimicrobial dressing (iodine-impregnated) and topical cream containing plant extracts [25]. However, there was no significant difference in healing between any types of dressings. Another Cochrane review of the same group included six studies $(n=375)$ compared ulcer healing of alginate dressings with basic wound contact dressings, foam dressings and a silver-containing, fibrous-hydrocolloid dressings. Results showed any significant differences in ulcer healing between alginate dressings and basic wound contact dressings. As well, a number of ulcers healed between anti-microbial (silver) hydrocolloid dressing and standard alginate dressing were not different [26].

\section{Conclusion}

In this review, some important considerations that need to be considered in the assessment of the wound and selection of dressing were discussed. Both conventional, as well as advanced dressings have some important advantages that can be achieved when using them at the precise time. Since, a single dressing is not appropriate for the whole journey of wound healing, selection of the dressing material imperative to be based on the wound bed condition. Incorporating of antibacterial agent is also important when necessary. Despite the treatment and dressing methods, healing duration of some ulcers are usually longer and, some ulcers do not heal in timely passion, while more severe ulcers need amputation. Thus, the necessity of testing new approaches has emerged as essential. 


\section{References}

1. Bajnok I, Grinspun D, Lloyd M, McConnell H, Mo J, et al. (2013) Assessment and management of foot ulcers for people with diabetes: second edition of RNAO's clinical practice guideline. Diabetic Foot Canada 1: 24-28.

2. Health Service Executive (2009) National best practice and evidence based guidelines for wound management, Ireland.

3. Dowsett C (2015) Breaking the cycle of hard-to-heal wounds: balancing cost and care. Wounds International 6(2): 17-21.

4. Vuorisalo S, Venermo M, Lepäntalo M (2009) Treatment of diabetic foot ulcers. J Cardiovasc Surg 50(3): 275-291.

5. Moura LI, Dias AM, Carvalho E, de Sousa HC (2013) Recent advances on the development of wound dressings for diabetic foot ulcer treatment-a review. Acta Biomater 9: 7093-7114.

6. Harding KG, Jones V, Price P (2000) Topical treatment: which dressing to choose. Diabetes Metab Res Rev 16(1): S47-S50.

7. Yazdanpanah L, Nasiri M, Adarvishi S (2015) Literature review on the management of diabetic foot ulcer. World J Diabetes 6(1): 37-53.

8. International Best Practice Guidelines (2013) Wound management in diabetic foot ulcers

9. Kavitha KV, Tiwari S, Purandare VB, Khedkar S, Bhosale SS, et al. (2014) Choice of wound care in diabetic foot ulcer: a practical approach. World J Diabetes 5(4): 546-556.

10. Mulder G, Armstrong DG, Seaman S (2003) Standard, appropriate, and advanced care and medical-legal consideration: Part one-diabetic foot ulcerations. Wounds 15(4): 1-17

11. McDonald A, Lesage P (2006) Palliative management of pressure ulcers and malignant wounds in patients with advanced illness. J Palliat Med 9: 285-295

12. Sibbald RG, Leaoer DJ, Queen D (2011) Iodine made easy. Wounds International 2(2): s1-s6

13. Angel DE, Morey P, Storer JG, Mwipatayi BP (2008) The great debate over iodine in wound care continues: a review of the literature. Wound Practice and Research 16(1): 6-21.
14. Vermeulen H, Westerbos SJ, Ubbink DT (2010) Benefit and harm of iodine in wound care: a systematic review. J Hosp Infect 76(3): 191-199.

15. Castro DLV, Santos VLCG (2015) Controlling wound odor with metronidazole: a systematic review. Rev Esc Enferm USP 49(5): 858863.

16. Bale S, Tebble N, Price P (2004) A topical metronidazole gel used to treat malodorous wounds. Br J Nurs 13(11): S4-S11.

17. Sampaio CPP, Biondo-Simoes MLP, Trindade LCT, Farias RE, Pierin RJ et al. (2009) Inflammatory alterations provoked by metronidazole in wounds: an experimental study in rats. Journal Vascular Brasileiro 8(3): 232-237.

18. Trindade LCT, Biondo-Simoes MLP, Sampaio CPP, Farias RE, Pierin RJ et al. (2010) Evaluation of topical metronidazole in the healing wounds process: an experimental study. Rev Col Bras Cir 37(5): 358-363.

19. Eaglstein WH (2001) Moist wound healing with occlusive dressings: a clinical focus. Dermatol Surg 27(2): 175-182.

20. Queen D, Orsted H, Sanada H, Sussman G (2004) A dressing history. Int Wound J 1(1): 59-77.

21. Hilton JR, Williams DT, Beuker B, Miller DR, Harding KG (2004) Wound dressings in diabetic foot disease. Clin Infect Dis 39(2): S100-S103.

22. Markakis K, Bowling FL, Boulton AJ (2015) The diabetic foot in 2015: an overview. Diabetes Metab Res Rev 32(1): 169-178.

23. Wu L, Norman G, Dumville JC, O’Meara S, Bell-Syer SE (2015) Dressings for treating foot ulcers in people with diabetes: an overview of systematic reviews. Cochrane Database Syst Rev 7: CD010471.

24. Dumville JC, Deshpande S, O’Meara S, Speak K (2013) Foam dressings for healing diabetic foot ulcers. Cochrane Database Syst Rev 6: CD009111.

25. Dumville JC, Deshpande S, O’Meara S, Speak K (2013) Hydrocolloid dressings for healing diabetic foot ulcers. Cochrane Database Syst Rev 8: CD009099.

26. Dumville JC, O’Meara S, Deshpande S, Speak K (2013) Alginate dressings for healing diabetic foot ulcers. Cochrane Database Syst Rev 6: CD009110.
Creative Commons Attribution 4.0 International License

For possible submissions Click Here

\section{Submit Article}

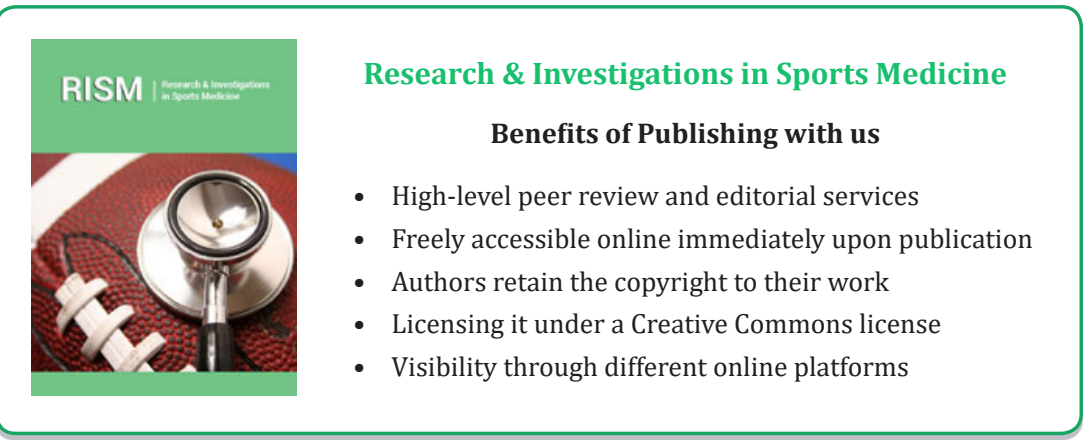

